\title{
New 5-Hydroxy-2-(hydroxymethyl)-4H-pyran-4-one Derivative Has Both Tyrosinase Inhibitory and Antioxidant Properties
}

\author{
Ho Sik Rho," Heung Soo Baek, Jae Won You, Sujong Kim, Jin Young Lee, Duck Hee Kim, and Ih Seop Chang \\ $R \& D$ Center, AmorePacific Corporation, Yongin, Gyeonggi 446-729, Korea. "E-mail: thiocarbon@freechalcom \\ Received November 18, 2006
}

Key Words : 5-IIydroxy-2-(hydroxymethyl)-4II-pyran-4-one, Derivative, Tyrosinase, Antioxidant

\begin{abstract}
Kojic acid,' 5-hydroxy-2-(hydroxymethyl)-4H-pyran-4one, is produced from carbohydrate sources in an aerobic process by a variety of microorganisms. It showed broad biological activities such as inhibition of tyrosinase, ${ }^{2}$ scavenging of the free radicals, ${ }^{3}$ chelating activity of metal ions ${ }^{4}$ and prevention of photodamage. ${ }^{3}$ Its various activities are due to $\gamma$-pyranone structure having enolic hydroxyl group. Recently, enolic hydroxyl group of kojic acid has been focused as an altemative of carboxylic acid in retinoid structure. We synthesized 3,4-methylenedioxy cinnamic acid ester of kojic acid as a new retinoidal compound. In this study, we evaluated biological activities of new kojic acid derivative $1,2-((3 E)-4(2 \mathrm{H}, 3 \mathrm{H}$-benzo[3,4-d]1,3-dioxolan-5yl)-2-oxo-but-3-enyloxy)-5-hydroxy-4H-pyran-4-one.
\end{abstract}

\section{Experimental Section}

Synthesis. Compound 1 was synthesized by the condensation of kojyl chloride with potassium salt of 3,4-methylenedioxy cinnamic acid. Structures of compounds and synthetic pathways are shown in Figure 1. Kojic acid was reacted with thionyl chloride to afford a kojyl chloride 2 . Then, kojyl chloride $\mathbf{2}$ was reacted with potassium salt of 3,4-(methylenedioxy) cinnamic acid to afford the final compound 1.

TLC, $\mathrm{SiO}_{2}, \mathrm{EtOAc}$ /hexanes $2: 1, \mathrm{R}_{\mathrm{f}}=0.4 \mathrm{I}^{\mathrm{I}} \mathrm{H}-\mathrm{NMR}(300$ $\left.\mathrm{MHz}, \mathrm{DMSO}-\mathrm{d}_{6}\right) \delta 9.20(\mathrm{bs}, 1 \mathrm{H}), 8.05(\mathrm{~s}, 1 \mathrm{H}), 7.58(\mathrm{~d}, 1 \mathrm{H}, J$ $=15.9 \mathrm{~Hz}), 7.39(\mathrm{~s}, 1 \mathrm{H}), 7.19(\mathrm{~d}, 1 \mathrm{H}, J=8.4 \mathrm{~Hz}), 6.90(\mathrm{~d}$, $1 \mathrm{H}, J=8.4 \mathrm{~Hz}$ ), 6.55 (d, IH, $J=15.9 \mathrm{~Hz}), 6.45$ (s, 1H), 6.02 $(\mathrm{s}, 2 \mathrm{H}), 5.00(\mathrm{~s}, 2 \mathrm{H})$. IR $v_{\text {nax }}(\mathrm{KBr}) 3206,1726 \mathrm{~cm}^{-1}$. Ms$\mathrm{FAB}(\mathrm{m} / \mathrm{e}) 317\left(\mathrm{M}^{+}+1\right)$.

Mushroom tyrosinase assay. Mushroom tyrosinase, Ltyrosine, and L-DOPA were purchased from Sigma Chemical (St. Louis, MO, USA). Tyrosinase activity was determined using the method of Pomerantz ${ }^{6}$ with minor modification. Twenty-five $\mu \mathrm{L}$ of $0.5 \mathrm{mM} \mathrm{L}-\mathrm{DOPA}, 25 \mu \mathrm{L}$ of $10 \mathrm{mM} \mathrm{L}-$ tyrosine, $875 \mu \mathrm{L}$ of $50 \mathrm{mM}$ phosphate buffer $(\mathrm{pH} 6.5)$, and
$25 \mu \mathrm{L}$ of test sample solution were mixed. Then $50 \mu \mathrm{L}$ of mushroom tyrosinase $(1600 \mathrm{U} / \mathrm{mL})$ was added. The amount of dopachrome produced in the reaction mixture was determined against a blank (solution without enzyme) at 475 $\mathrm{nm}\left(\mathrm{OD}_{475}\right)$ using a spectrophotometer (Shimadzu Corporation, Kyoto, Japan).

MTT growth assay. HaCaT keratinocytes were maintained in DMEM (Gibco, Grand Island, NY, USA) supplemented $10 \%$ fetal bovine serum, previously inactivated at $56^{\circ} \mathrm{C}$ for $20 \mathrm{~min}$. The cytotoxic effects of test materials were monitored by 3-(4,5-dimethylthiazol-2-yl)-2,5-diphenyltetrazolium bromide (MTT) assay as dose dependent manner.

Lipid peroxidation. $\mathrm{HaCaT}$ keratinocytes were grown in DMEM medium containing $10 \%$ fetal bovine serum and $1 \%$ antibiotic and antimycotic solution. For experiments, cells were maintained in DMEM supplemented with $1 \%$ fetal bovine serum (FBS) and test materials for $18 \mathrm{~h}$. After $\mathrm{HaCaT}$ keratinocytes were incubated with test materials for $18 \mathrm{~h}$, the cells were exposed to $4 \mathrm{mM} t-\mathrm{BOOH}$ for $4 \mathrm{~h}$. Following incubation, the cell were washed twice with phosphate-buffered saline (PBS), and lysed by repetitive freeze/thawing in distilled water. To establish the levels of lipid peroxidation, malondialdehyde (MDA) and 4-hydroxy2(E)-nonenal (4-HNE) levels were quantified using a commercial colorimetric lipid peroxidation assay kit (Calbiochem, San Diego, CA). This method analyzes MDA and 4-HNE by their reaction with a chromogen ( $N$-methyl-2-phenylindole) at $45^{\circ} \mathrm{C}$ to produce a stable chromogen. The reaction products were measured by spectrophotometry at $586 \mathrm{~nm}$. The procedure was performed in accordance with the manufacturer's specifications and data were expressed in $\mathrm{mmol} /$ mg protein.

\section{Results and Discussion}

Compound $\mathbf{1}$ is a kojic acid derivative which possesses an ester linker between kojic acid and 3,4-(methylenedioxy)-

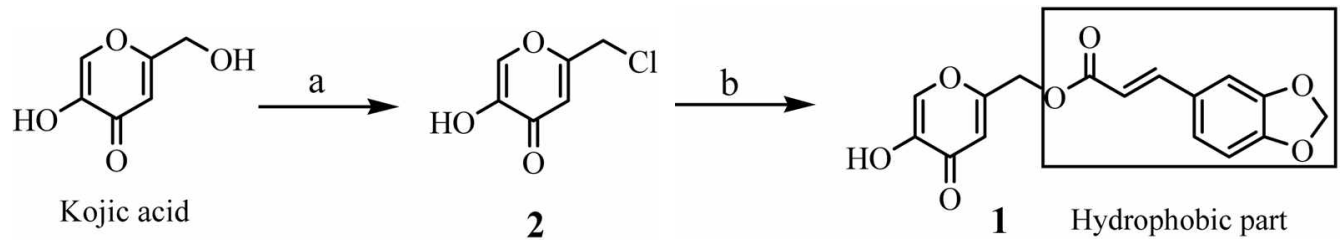

Figure 1. Reaction conditions; (a) SOCl, DMF; (b) Potassium salt of 3,4-(methylencdioxy)cinnanic acid, DMF. 


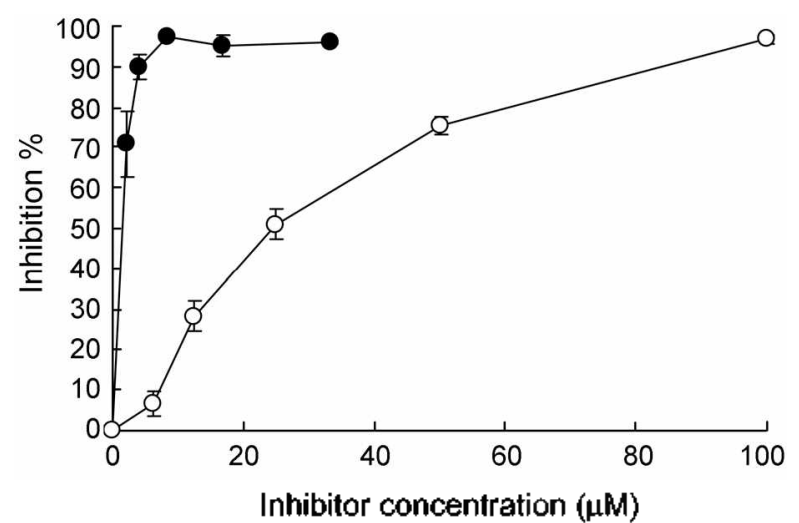

Figure 2. Dose-dependent inhibitory effects on mushroom tyrosinasc by compound 1 and kojic acid. Samples shown are compound $\mathbf{l}$ (closed circle) and kojic acid (open circle). Effect on tyrosinase activity by samples as a finction of concentration are represented as inhibition $\%$, means $\pm S$.E. of the threc independent tests.

cinnamate moiety. Cinnamate group was introduced as a hydrophobic moiety to increase tyrosinase inhibitory activity of kojic acid. The mushroom tyrosinase inhibitory activities of compound 1 and kojic acid were determined using Ltyrosine as substrate. When L-tyrosine was used as a substrate, compound $\mathbf{1}$ showed stronger inhibitory activity than that of kojic acid. $\mathrm{IC}_{50}$ of compound 1 is $1.4 \mu \mathrm{M}$ (Fig. 2 ).

A kinetic study of L-tyrosine oxidation catalyzed by mushroom tyrosinase was accomplished in the presence of compound 1 and kojic acid (Fig. 3). Compound 1 and kojic acid showed the same Michaelis-Menten constant $\left(\mathrm{K}_{\mathrm{m}}\right.$ value). It means that the same moiety was used for inhibitory effects on the mushroom tyrosinase. Through LineweaverBurk plot data, compound 1 was a competitive inhibitor.

Another expected biological activity of compound $\mathbf{1}$ is an antioxidant effect. Recently, kojic acid showed inhibitory activity in lipid peroxidation. ${ }^{3} 5$-Hydroxyl group of kojic acid is regarded as a hydrogen donor that results in radical scavenging activity. Cytotoxicity and inhibitory potency of compound 1 in lipid peroxidation was compared with known antioxidant agents such as trolox, ${ }^{7} \mathrm{EGCG}^{8}$ and kojic acid. Cell viability was assessed by the MTT reduction assay. $\mathrm{HaCat}$ cells were resistant to up to $10 \mu \mathrm{M}$ concentration for all test materials.

After confinming cell viability, we evaluated inhibitory activity of compound $\mathbf{1}$ and known antioxidants. Their activities were examined in terms of ability to reduce the oxidative factors such as malondialdehyde (MDA) and 4hydroxy-2(E)-nonenal (4-HNE), generated by TBHP (tertbutylhydroperoxide) in $\mathrm{HaCaT}$ cell line. ${ }^{9}$ Treatment of 4 $\mathrm{mM}$ of TBHP increased lipid peroxide level up to about three times as compared with untreated sample. When 10 $\mu \mathrm{M}$ of compounds were treated, trolox, EGCG and compound 1 were active (Fig. 4). Compound 1 decreased the level of lipid peroxidation by about $47 \%$ in contrast with TBHPtreated control. However, kojic acid showed no inhibitory activity at $10 \mu \mathrm{M}$ concentration.

Compound 1 showed more potent biological activities

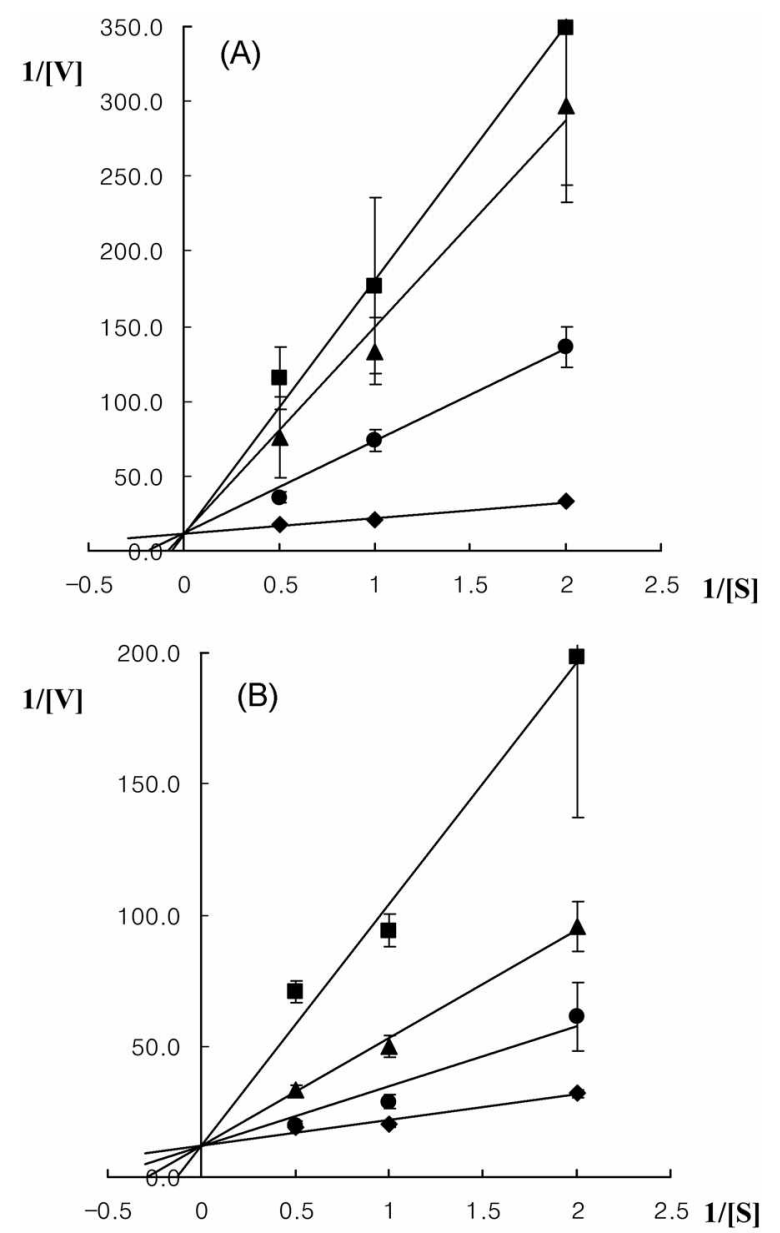

Figure 3. Lineweaver-Burk plot of mushroom tyrosinase on the presence of compound 1 and kojic acid. Data were obtained as mean value of $T[V]$, inverse of the increase of optical density at $450 \mathrm{~nm}$ per min. (OD450/min), of three independent tests with different concentrations of L-tyrosine as a substrate. $(\Lambda)$ with 10 $\mu \mathrm{M}$ (rectangle), $5 \mu \mathrm{M}$ (triangle), $2 / \mathrm{M}$ (circle), or no compound 1 (diamond) and kojic acid (B) with $100 \mu \mathrm{M}$ (rectangle), $50 \mu \mathrm{M}$ (triangle), $20 \mu \mathrm{M}$ (circle), or no kojic acid

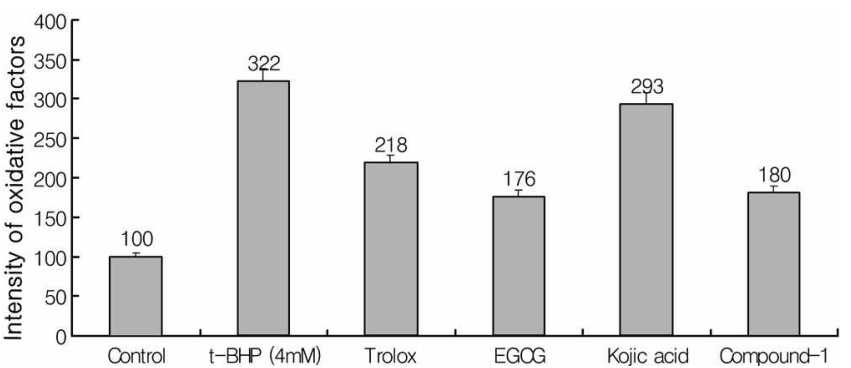

Figure 4. Inhibitory effects on lipid peroxidation induced by TBHP in $\mathrm{HaCat}$ cell line. All compounds were tested at $10 \mu \mathrm{M}$ concentration.

than those of kojic acid in two tested methods. These results suggest that biological activities of kojic acid were increased by the addition of 3,4-(methylenedioxy) cinnamate moiety as a hydrophobic part. Kojic acid is hydrophilic compound because it has two hydroxyl groups in 2 and 5 positions. Compound 1 is believed to be more adequate in cell permeation than kojic acid because of its balance in hydrophilic 
Table 1. Calculation of $\log P$ values

\begin{tabular}{cc}
\hline Compound & Log $\mathrm{P}^{\prime \prime}$ \\
\hline Kojic acid & -1.111 \\
Compound $\mathbf{1}$ & 1.169 \\
\hline
\end{tabular}

'Log P: Log[octanol/water] partition coeflicient

and hydrophobic character. To compare hydrophobic character of compound 1 with kojic acid, we calculated lop $\mathrm{P}$ value (Table 1).

In conclusion, pharmacophore of kojic acid is enolic hydroxyl group in 5-position. To enhance biological activities of kojic acid, we increased hydrophobicity by introduction of 3,4-methylenedioxy cinnamate moiety in 2-position which is not pharmacophore. Its potent activities may be due to balance between hydrophilic and hydrophobic character.

\section{References}

1. (a) Burdock, G A.; Soni, M, G; Carabin, I. G Regndatory;
Toxicology and Pharmacolog: 2001, 33, 80. (b) Futamura, T.; Okabe, M.; Tamura, T.; Toda, K.; Matsunobu, T.; Park, Y. S. $J$. Biosci. Bioeng. 2001, 91, 272. (c) Ohyama, Y.; Mishima, Y. Fragrance J. 1990, 6, 53 .

2. Kobayashi, Y.; Kayahara, H.; Tadasa, K.; Tanaka, H. Bioorg. Med. Chem. Lett, 1996, 6, 1303.

3. Mitani, H.; Koshishi, I.; Sumita. T.; Imanari, T. Etr. J. Pharmacol. $2001,411,169$.

4. Yuen, V. G; Caravan, P.; Gelmini, L.; Glover, N.; Mcneill, J. H.; Setyawati, I, A.; Zhou, Y,; Orvig, C. J. Inorg. Biochem, 1997, 68, 109 .

5. Kim, M. S.; Lee, S.; Rho, H. S.; Kim, D. H.; Chang, I. S.; Chung, J. H. Clinica. Chinica. Acta 2005, 362, 161.

6. Pomerantz, S. H. J. Biol. Chem. 1963, 238, 2351.

7. (a) Peus, D.; Meves, A.; Pott, M.; Beyerle, A.; Pittelkow, M. R. Free Radic, Biol. Med. 2001, 30, 425. (b) Delicado, E. N.; Ferrer, A. S.; Carmona, F. G Biochim. Biophys. Acta. General Subjects $1997,1335,127$.

8. (a) Saffari, Y.; Hossein Sadrzadeh, S. M. Life Sciences 2004, 74, 1513. (b) Bors, W.; Michel, C. Free Radic. Biol. Med. 1999, 27, 1413.

9. Rho, H. S.; Baek, H. S.; Lee, B. S.; Kim, J. H.; Kim, D. H.; Chang, I. S. Bull, Korean Chem. Soc. 2006, 27, 115. 